\title{
Contrasting responses of plants and pollinators to wood- land disturbance
}

\author{
CAROLINA COULIN, ${ }^{1 \star ~(D) ~ M A R C E L O ~ A . ~ A I Z E N ~}{ }^{2}$ AND LUCAS A. GARIBALDI ${ }^{1}$ \\ ${ }^{1}$ CONICET-Instituto de Investigaciones en Recursos Naturales, Agroecología y Desarrollo Rural \\ (IRNAD), Sede Andina, Universidad Nacional de Río Negro, Bariloche (Email: \\ ccoulin@unrn.edu.ar); and ${ }^{2}$ CONICET-Laboratorio Ecotono, INIBIOMA, Universidad Nacional del \\ Comahue, Bariloche, Argentina
}

\begin{abstract}
Preserving species diversity is critical to ensure ecosystem functioning; however, different components of diversity might respond to human disturbance in different ways. Similarly, trophic levels might have uncoupled responses to the same disturbance, thus ameliorating or aggravating the persistence of ecological communities. In this study, we analysed how the density, richness and evenness of flowers and pollinators respond to four levels of woodland thinning intensity $(0,30,50$ and $70 \%$ of woodland basal area removed) over 2 years in three contrasting sites. We found a mismatch in the response of flowers and pollinators to thinning. Flower density and richness had disparate responses, depending on the site and year, while evenness did not change with thinning. In contrast, pollinator density and richness, but not evenness, consistently increased with thinning among years and sites. These results suggest that thinning has a great influence on pollinators through changes in abiotic conditions and, perhaps, flower attractiveness rather than through small-scale changes in flower density and richness. At the site where tree flowers were absent, bee pollinator community composition was impoverished, suggesting that trees provide important floral resources to pollinators. Our findings indicate that disturbance may diminish local plant abundance and richness, but pollinator abundance and richness are enhanced after intense thinning at small scales.
\end{abstract}

Key words: animal-plant interaction, forest disturbance, pollinator diversity, temperate woodlands, thinning intensity.

\section{INTRODUCTION}

Human disturbances induce changes in local species diversity and abundances of natural communities (Winfree et al. 2007; Hautier et al. 2015; Newbold et al. 2016). However, it is unclear whether species at different trophic levels respond in different ways to a given disturbance. A possible mismatch in the response to disturbance between trophic levels is particularly interesting in the case of flower and pollinator communities, since $>85 \%$ of flowering plants depend on animal pollination for their reproductive performance (Ollerton et al. 2011). There is increasing evidence supporting that pollinator abundance and richness usually enhance plant reproductive success (Fontaine $e t$ al. 2006; Frund et al. 2013; Garibaldi et al. 2013), whereas flower abundance and richness promote pollinator richness (Blaauw \& Isaacs 2014a,b; Vrdoljak et al. 2016). Anthropogenic disturbances are usually related negatively to native bee abundance and richness (Winfree et al. 2016). However, the magnitude and direction of human-induced changes on flowers and pollinators vary depending on disturbance type and

${ }^{\star}$ Corresponding author.

Accepted for publication April 2019.

C 2019 Ecological Society of Australia intensity (Aizen \& Vazquez 2006). Understanding the way in which plants and pollinators respond to human disturbances will improve our capacity to predict effects on plant reproduction and on the trajectory of ecological systems.

The response of the diversity of sessile organisms, such as plants, to disturbance is expected to be unimodal. In particular, the intermediate disturbance hypothesis (Connell 1978; Huston 2014) predicts that plant diversity reaches its maximum at intermediate levels of disturbance. At low levels of disturbance, diversity is reduced because of competitive exclusion, whereas at high levels of disturbance only the most tolerant species persist. However, how plant diversity responds to disturbance depends not only on disturbance intensity and frequency, but also on site productivity as the dynamic equilibrium model posits; hence, maximum diversity can be promoted at lower or higher levels of disturbance according to local productivity (Grime 1973; Huston 1979, 2014). Despite having received strong criticism (Fox 2013), these theories explain observed patterns of local diversity of sessile organisms across disturbance gradients (Connell 1978). Other factors seem to have an important influence in the relationship between diversity of mobile organisms and disturbance (Huston 2014). 
Predicting pollinator diversity response to disturbance may be more challenging than plants' response. According to the bottom-up theory (Hunter \& Price 1992; Siemann 1998), plant richness has strong effects on species abundance and richness at upper trophic levels (Scherber et al. 2010). If floral resources become scarce or are delivered by only a few species, we would expect pollinator abundance and diversity to decline, while the opposite would be expected if floral resources become plentiful or more diverse. Therefore, we would expect at first that disturbance effects on pollinators to resemble those of plants; hence, a unimodal response to disturbance would be expected following the intermediate disturbance hypothesis. However, disturbance usually changes many other biotically related factors, for example vegetation structure (Sekercioglu 2002; Cavallero et al. 2015), as well as abiotic factors, for example light (Aizen \& Vazquez 2006; Burgess et al. 2006) that may govern the response of pollinators more than the effect of taxonomic plant diversity (Brose 2003). Consequently, a more linear response of pollinator diversity to disturbance intensity would be expected.

Forest thinning is an anthropic disturbance that may affect pollinator communities indirectly, through effects on the plants on which they forage, or directly, through changes in environmental factors. Thinning consists of the removal of woody aerial biomass, generating changes in vegetation structure and competition among plants, additionally to changes in abiotic variables, such as increases in temperature (Weng et al. 2007) and light (Canham et al. 1990). The resources released from biomass removal, commonly result in positive effects on plant species diversity (Gerstner et al. 2014) and may enhance both flower abundance and richness (Pengelly \& Cartar 2010). In addition, it can also affect physiological plant attributes related to flower visitor attractiveness such as floral display (Cunningham 1997), phenology (Paritsis et al. 2006) and nectar and pollen quantity and quality (Boose 1997; Etterson \& Galloway 2002; Chalcoff et al. 2006). Conversely, changes in abiotic conditions after thinning may be radical, with higher temperatures and solar radiation increasing plant water stress and reducing floral resources. Although floral resources are generally the main variable positively related to pollinators (Aizen \& Vazquez 2006), their response to thinning is likely to depend also on environmental conditions affecting their mobility traits, physiological tolerances and nesting resources (Williams et al. 2010). Thus, pollinator responses will depend on the size of the affected area and surrounding landscape context. Some previous studies have reported decreasing pollinator abundance and diversity in crops with increasing distance to natural areas or forest cover, demonstrating these habitats can be essential for many pollinators (Garibaldi et al. 2011; Saturni et al. 2016). In contrast, other studies report impoverished pollinator communities with increasing forest cover, a pattern probably related to decreased flower and nesting resource availability in the shaded understory of dense tree canopy (Winfree et al. 2007; Pengelly \& Cartar 2010; Rodríguez \& Kouki 2017). The direction and magnitude of local pollinator responses to anthropic disturbances, such as thinning, may thus depend on local resource complementarity and landscape context.

Mixed Nothofagus antarctica forests and shrublands of North West Patagonia (NWP) are particularly interesting for studying flower-pollinator responses to thinning, because the flora of this region has a great dependency on animal pollination (Aizen \& Ezcurra 1998). In this region, $85 \%$ of the woody genera depend on animal pollination, and approximately $70 \%$ of these genera are pollinated by insects (Aizen \& Ezcurra 1998), such as the showy protandrous flowers of Alstroemeria aurea (Aizen 2001). In these woods, the main anthropogenic disturbance is represented by cattle grazing (Reque et al. 2007). Invasive species, including exotic conifers (Lantschner \& Rusch 2007), are also commonly introduced after disturbance at these sites, with possible effects on flower-pollinator interactions (Morales \& Aizen 2006). Even though optimal management is needed, the use of thinning as an alternative sustainable resource exploitation strategy has not been explored in NWP (Rusch et al. 2017). In this context, because pollination changes have the potential to affect vegetation community structure, it is important to assess whether thinning introduces changes in floral resources and their pollinators, and whether those changes may be moderated by disturbance intensity. In this study, we investigated how thinning intensity affects both plant and pollinator communities, using experimental plots at three different shrubland sites. As diversity incorporates both richness and evenness, we analysed density, richness and evenness responses separately. Further, analyses were conducted separately at the plant and flower level, to identify whether differences are related to plant density or whether thinning also alters the number of flowers per individual. For plants and flowers, we expected a unimodal response to thinning in line with the intermediate disturbance hypothesis (Grime 1973; Huston 2014). As pollinators depend on floral resources, but also are expected to be greatly affected by abiotic factors, we predict a mismatch in the responses of flowers and pollinators to disturbance.

\section{METHODS}

\section{Study system and experimental design}

Shrublands in North West Patagonia (NWP) are dominated by wind-pollinated $N$. antarctica (Fagaceae), but 
animal-pollinated Lomatia hirsuta (Proteaceae), Diostea juncea (Verbenaceae) and Schinus patagonicus (Anacardiaceae) are also found in abundance. In NWP, the slopes and valleys present a diversity of conditions in terms of solar radiation and water dynamics. This creates a heterogeneous landscape in terms of productivity, species composition and potential responses to thinning disturbance.

This study was carried out nearby the localities of 'El Foyel' (S $41^{\circ} 38^{\prime} 47^{\prime \prime}, \mathrm{W} 71^{\circ} 29^{\prime} 55^{\prime \prime}$ ) and 'Los Repollos' (S $41^{\circ} 46^{\prime} 32^{\prime \prime}$, W $71^{\circ} 28^{\prime} 18^{\prime \prime}$ ), Río Negro province, in NWP (Appendix S1). The study region is a forest/steppe ecotone, with broad-leaf mixed shrublands dominated by $N$. antarctica. In order to account for shrubland heterogeneity, we selected three contrasting sites which, among other characteristics, differ in species composition, canopy profile, tree height, and slope degree and orientation. The first site, referred hereafter as 'Tall', is a shrubland with the highest tree height (maximum stratum height between 5 and $8 \mathrm{~m}$ ) located on a south-facing slope nearby El Foyel. Other woody species found at the site include D. juncea, S. patagonicus, L. hirsuta and Embothrium coccineum (Proteaceae). The 'Medium' site is a mid-tall shrubland (maximum height between 3 and $5 \mathrm{~m}$ ). It is located on a north-facing slope and composed mainly of N. antarctica, S. patagonicus, L. hirsuta, Fabiana imbricata (Solanaceae) and E. coccineum. The third site, the 'Short' shrubland (height between 1.5 and $3 \mathrm{~m}$ ), is located at the bottom of a valley nearby Los Repollos. The tree stratum is only composed of $N$. antarctica and, in contrast to the other sites, individuals are stunted. The Tall and Medium shrubland sites are located on the south and north faces of the same hill; thus, they are at least $200 \mathrm{~m}$ apart, and both are $14.3 \mathrm{~km}$ from the Short shrubland site. At each site, we established eight $31.5 \times 45 \mathrm{~m}$ plots and randomly assigned them to one of the following thinning treatments: $0,28.6,47.6$ and $66.7 \%$ of the basal area removed (hereafter referred as $0,30,50$ and $70 \%$, respectively). Two replicates of each treatment were present at each site. Plots from the same site were contiguous with one another, and although for logistical reasons, some plots were closer than others, and the distance between the most distant plots within a site never exceeded $400 \mathrm{~m}$. Within a plot, a given thinning treatment was applied by cutting all woody plants at the base along six equidistant rows of $45 \mathrm{~m}$ with a varying width $(1.5,2.5$ or $3.5 \mathrm{~m}$ according to the thinning level). Thinning was applied once between 2013 and 2014 (beginning of 2013 for Tall shrubland, end of 2013 for Short shrubland and beginning of 2014 for Medium shrubland). Fieldwork was carried out during the austral flowering season, from 24 October 2014 to 30 January 2015 and from 22 October 2015 to 20 January 2016, hereafter 'Year 1' and 'Year 2', respectively.

\section{Vegetation survey}

The total number of individual plants, number of flowering individuals, number of open flowers and total number of flowers (including flower buds, open flowers, old flowers and fruits) per individual were recorded in two circular subplots ( $4 \mathrm{~m}$ of radius) per plot. One subplot was located at the centre of each plot while the second subplot was located in a randomly allotted position. In order to sample flowering individuals and open flowers as the flowering season progressed, plots were visited every 15-20 days. For herbs and shrubs, as density is higher and distance among individuals lower than for trees, we only surveyed half of the subplot area $\left(25.1 \mathrm{~m}^{2}\right)$. For species from the Asteraceae family, flower heads were counted as flower units. For species with $>300$ flowers per individual, we estimated flower number by counting the number of flowers on one branch and multiplied this by the number of branches (or the equivalent volume of flowers of the branch) on each individual. As we were interested in how flower resources and plant flowering respond to thinning, non-flowering trees $(<1.5 \mathrm{~m}$ high $)$ and non-entomophilous species were not included in the survey. After consulting with taxonomists, we identified a total of 65 plant species/morphospecies (Instituto de Botanica Darwinion 2016).

\section{Pollinator surveys}

Since all flower insect visitors are potential pollinators, we considered that all visitors contacting flower reproductive parts were potential pollinators. For each flowering species in each plot, number and identity of pollinators were recorded during 10-min censuses on sunny or partially cloudy days between 09:30 and 19:00 h. All plots of the same site were surveyed on the same days, and the order in which plots were visited was randomised to avoid possible 'day' and 'time of the day' confounding effects among plots. When possible, in order to consider possible variation due to time of day in pollinator activity, we surveyed each plot twice during the same sampling day (once in the morning and once in the afternoon) and then averaged these observations, so that we had one count per flowering species per plot per survey day. The number of sampling observations varied across species, plots and sites because species differ in flowering duration, abundance and spatial distribution. If weather conditions were suitable, the three sites were visited in the same week, and each site was surveyed approximately once a week during the flowering season of both years. In total, we conducted 3079 pollinator censuses $(513.16 \mathrm{~h})$, but as some observations were replicated on the same day, we ended up with 2033 separate observations after averaging observation per species per plot per day. When possible, unknown pollinators were captured for identification. With the support of taxonomists, individuals were identified to the lowest taxonomic level possible. Individuals that could not be identified to species level or could not be distinguished in the field were grouped by morphotypes. Although we might be underestimating species richness by pooling several species as a same morphotype, we do not expect that it affects relative differences among plots. Altogether we identified 73 species/morphotypes. It is important to note that we only evaluated the activity of pollinators in response to thinning, rather than their demographic response, as the spatial configuration of our experiment and plot sizes allows mobile organism to move among treatment plots. This means that pollinators may be using flowers and other resources from more than one treatment plot sequentially. Thus, our objective was to 
assess changes in pollinator abundance conditioned by thinning intensity at the local scale.

\section{Response variables}

As some herbs are not present for the whole flowering season, plant density data correspond to the data recorded during each species peak flowering time. To account for flower density over time, flower density was averaged across all survey dates for each subplot. Flower richness was estimated based on the number of flowers of each species at its peak flowering time. For pollinators, in order to estimate the mean daily pollinator density per plot (No. $\min ^{-1} \mathrm{~m}^{-2}$ ), we summed the number of pollinators per flower per minute from observational records and multiplied this by flower density of the corresponding species for each plot and date. Pollinator richness was estimated with each observation record as a sample using EstimateS software 9.1.0 (Colwell 2013). We considered Chaol as the most appropriate richness index, given that our samples differ in size because pollinators' attraction vary among flowers and plots (Hortal et al. 2006). For evenness, we used the Eve function from the Fundiv package, which wraps the Vegan package (Oksanen et al. 2017) and calculated the EinvD index following the recommendation of Smith and Wilson (1996). These authors recommend EinvD, especially when it is necessary for the index to respond adequately to an evenness gradient and be less affected by species with low abundance.

\section{Statistical analyses}

We evaluated the effects of thinning intensity on the response variables (plant density, plant richness, plant evenness, flower density, flower richness, flower evenness, pollinator density, pollinator richness and pollinator evenness) using generalised linear mixed-effects models, implemented in the lme function from the nlme package (Pinheiro et al. 2017) of the $\mathrm{R}$ software ( $\mathrm{R}$ Core Team 2018). We modelled variances using VarIdent function for categorical variables, varExp function for numeric variables and VarComb when response variables were both numeric and categorical. Density response variables were log transformed when necessary. We included 'Thinning2', the square of thinning, because we expected non-linear responses, in line with the intermediate disturbance hypothesis. The predictor variables included as fixed effects were 'Thinning' (numerical), 'Thinning2' (numerical), 'Site' (categorical), 'Year' (categorical), and the two-way and three-way interactions of 'Thinning' and 'Thinning2' with 'Year' and 'Site'. The 'plot' effect was always included as a random effect. Despite our design being spatially explicit, by including 'Site' as a random factor implying spatial dependence, we tested for spatial autocorrelation by assessing the semivariogram on the residuals of each model. We selected best fitting models based on Akaike's Information Criterion (AIC), using the function dredge from the package MuMin (Bartón 2016). Relative importance values were calculated with the importance function in the package MuMin, which sums the 'Akaike weights' over all models including explanatory variables.

\section{RESULTS}

\section{Site level differences}

In general, most variability in the models was captured by Site (Figs 1, 3 and Appendix S3). Plant density was generally higher at the Short shrubland and lower at the Tall shrubland site, while flower and pollinator density were generally higher at the Tall shrubland and low at the Short shrubland site (Figs 1, 2 and Appendix S2). In contrast, plant and flower richness had the highest values at the Medium shrubland site, while pollinator richness was similar in all three sites (Fig. 3, Appendix S4).

In the Tall shrubland site, the most abundant flowers were from woody vegetation, including the shrub species Discaria Chacaye (Rhamnaceae), S. patagonicus and Maytenus sp. (Celastraceae). The most common pollinators were the sweat bee Ruizanthedella mutabilis (Halictidae) and a group consisting of Heterosarus sp. (Andrenidae), Halictillus reticulatus (Halictidae) and Lasioglossum (Dialictus) sp. (Halictidae) (grouped together as they were indistinguishable in the field), followed by the sweat bee Corynura aureoviridis (Halictidae; Appendix S2). In the Medium shrubland site, the most abundant flowers were found in woody vegetation, including $S$. patagonicus, $L$. hirsuta and F. imbricata. The most common pollinators were ants (Formicidae) and the same bees that dominated at the Tall shrubland site (Appendix S2). In the Short shrubland site, the main floral resources were provided by herb stratum, including Baccharis maguellanica (Asteraceae), Gamocarpha selliana (Calyceraceae) and Quinchamalium chilense (Schoepfiaceae) and the most common pollinators were coleopterans belonging to the Buprestidae family (Appendix S2).

\section{Density, richness and evenness correlations}

Pollinator density was highly correlated with flower density in both years (Table 1). Plant density had a negative or null relationship with flower and pollinator densities as well as all other variables. Plant richness was positively related to flower and pollinator density (Table 1). Flower density was negatively related to plant density in the first year, but this association was weaker in the second year (Table 1). Plant, flower and pollinator richness were all positively related, although plant-pollinator richness relationships were generally weak (Table 1 ).

Focusing on the relationship between the three indicators at each level, evenness had a negative or no evident relation with density and richness, and the same happened with evenness among plants, flowers 

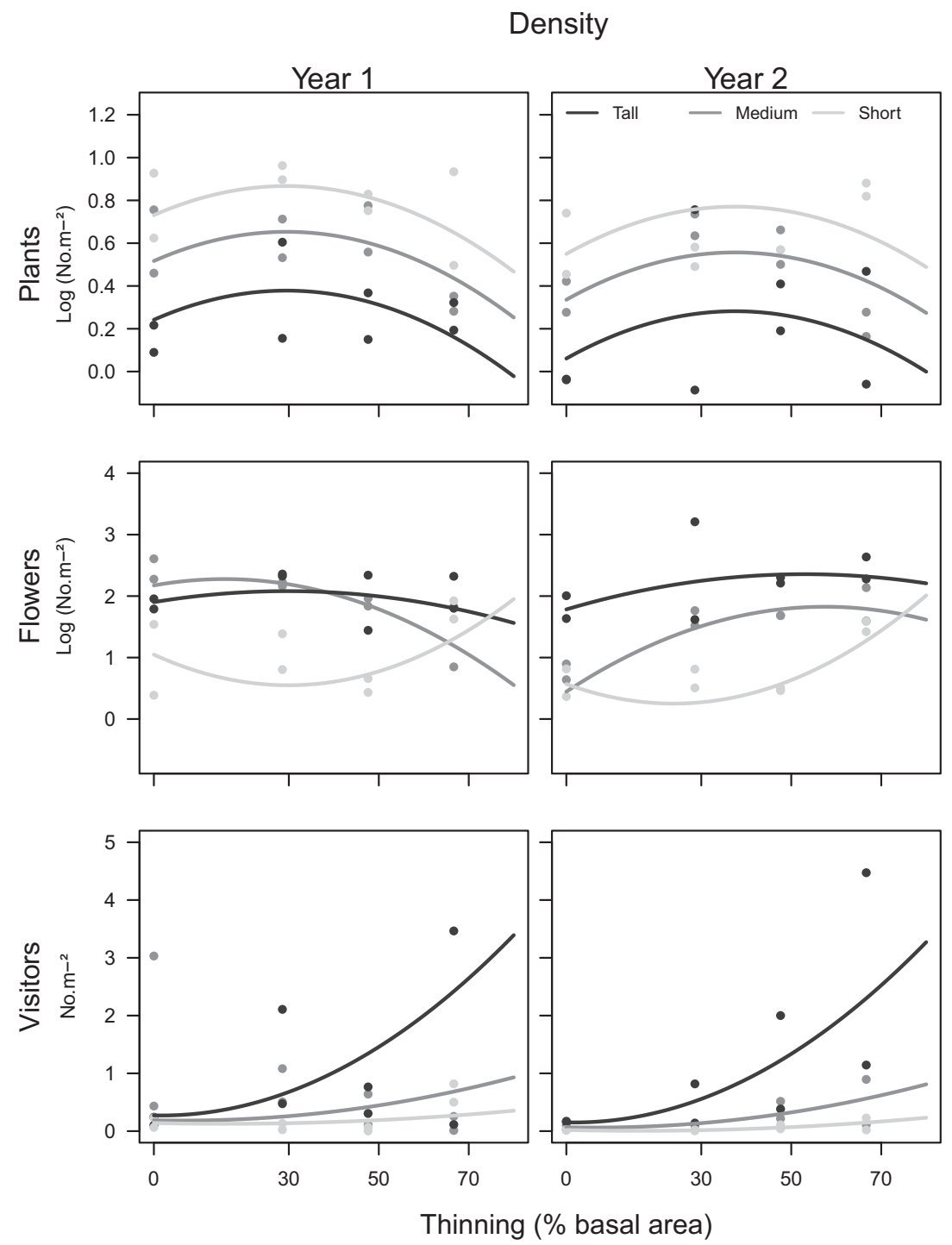

Fig. 1. Plant, flower and pollinator density. Plant, flower and pollinator density responses to thinning intensity in three forest sites in north-western Patagonia with contrasting tree height ('Tall', 'Medium' and 'Short'). Each point is the average value of a plot, and lines are the predicted values.

and pollinators (Table 1). Richness relationships with density, although not always significant, were negative for plants and positive for flowers and pollinators (Table 1).

\section{Thinning effects}

Thinning explained part of the variation in almost all response variables (Appendices S3 and S4). In all the regression models, there was a quadratic response to thinning (Appendices S3 and S4), although in some cases this quadratic term was negative (decelerating increase, i.e. plant density) and in others positive (accelerating increase, i.e. pollinator density). Density variation in plants, flowers and pollinators was explained by thinning intensity, year and site (Appendices S3 and S4).

Even though pollinator density was strongly associated with flower density (Table 1), thinning treatment changed that pattern in two of the three sites. During the first year, flower density increased (Short shrubland), decreased (Medium shrubland) or remained the same (Tall shrubland) along the thinning intensity gradient. In the second year, flower density increased slightly (Tall shrubland) or sharply (Short shrubland) with increasing thinning (Figs 1, 2). Instead, pollinator density increased with thinning intensity both years. Moreover, at the site where thinning intensity had the smallest effect on flower density (Tall shrubland), it had the largest effect on pollinator density and viceversa. Plant density was 


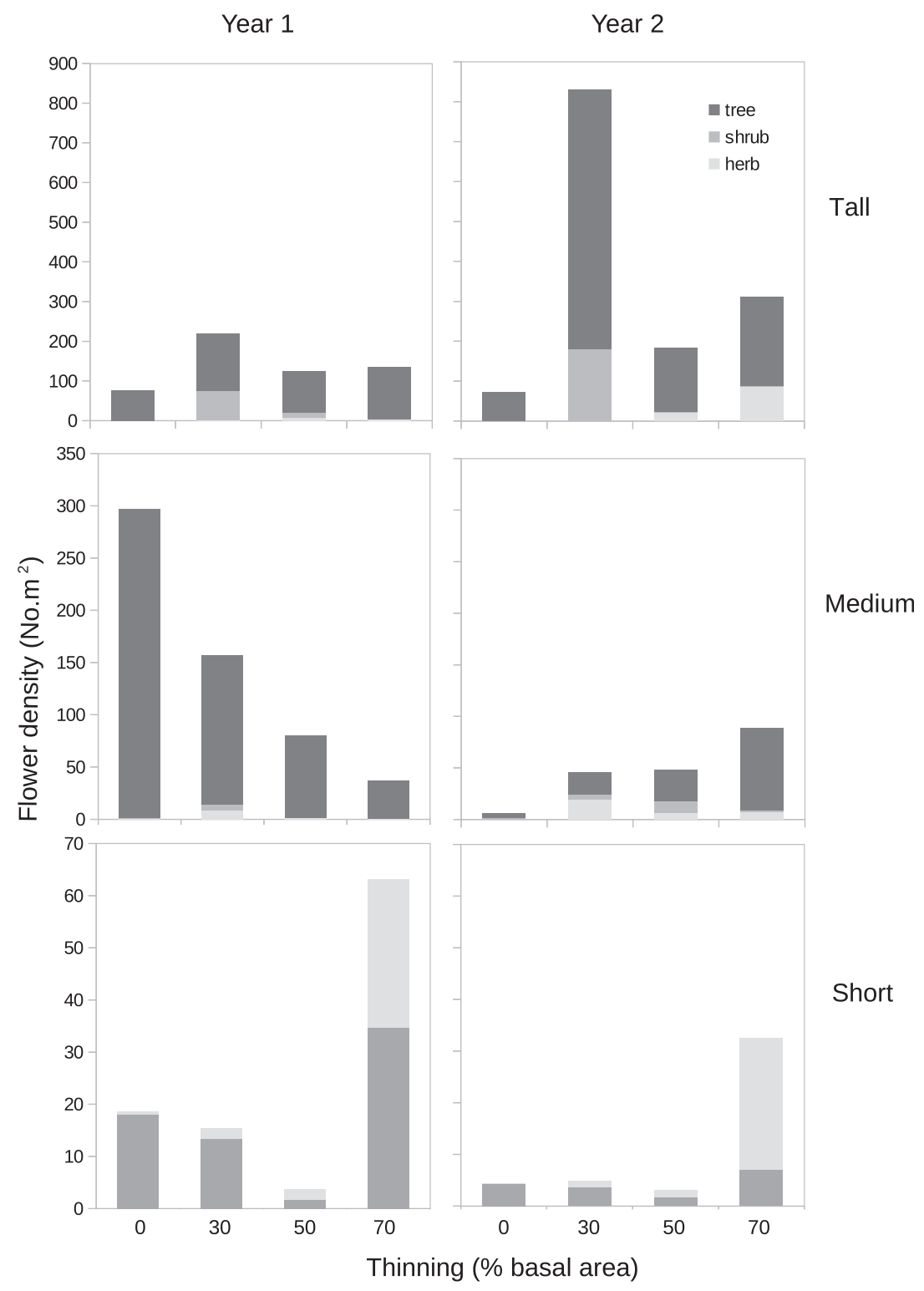

Fig. 2. Herb, shrub and tree flower density. Herb, shrub and tree flower density responses to thinning intensity in three forest sites in north-western Patagonia with contrasting tree height ('Tall', 'Medium' and 'Short').

always greater in plots with lower and medium thinning intensities (Fig. 1), suggesting that although thinning removed trees, it favoured the growth of more herbs at moderate intensities. However, at the Tall and Medium shrublands, trees were always the main floral resource, and except for the first year at the Medium shrubland, tree flower density always increased at some level of thinning (Fig. 2). In consequence, at high level of thinning, flower density did not decrease with the same general pattern as plant density, highlighting the differences among communities in flowering response.

Thinning effects on richness differed among plants, flowers and pollinators. Pollinator richness increased sharply with thinning and did not vary with Site or Year (Fig. 3, Appendices S3 and S4, Appendix S2), while flower richness had unimodal responses with maximum values at low, intermediate or high intensities depending on the site. In both years, plant richness decreased with thinning in the Medium shrubland site and increased at the Tall and Short shrublands (Fig. 3). Again, differences between plant and flower responses make evident a thinning effect on flowering that differs among sites.

Consistent changes in evenness with thinning were only observed for pollinators (Appendices S3 and S4, and Fig. 4). In this case, pollinator evenness marginally decreased with thinning intensity (Fig. 4). 

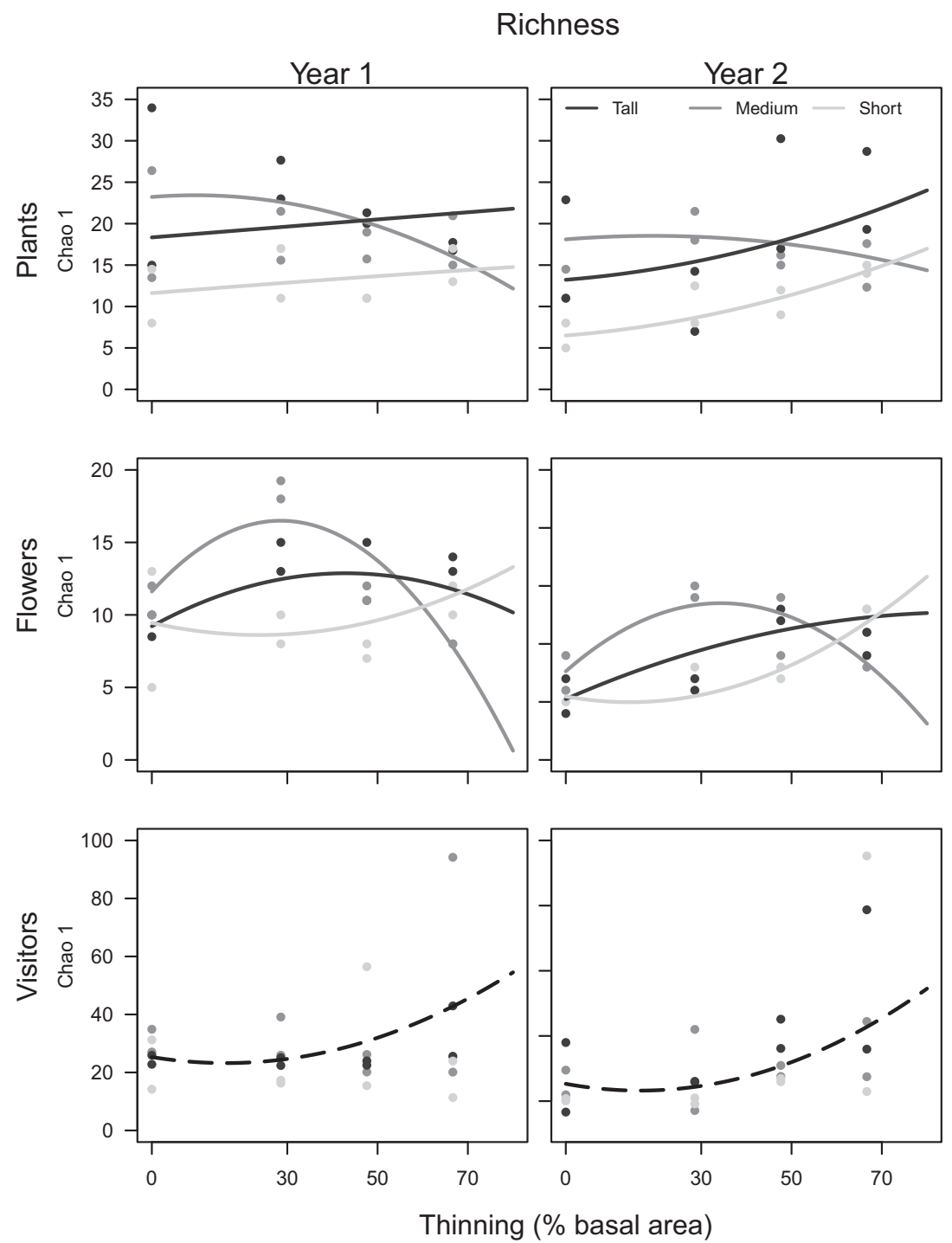

Fig. 3. Plant, flower and pollinator richness. Plant, flower and pollinator richness responses to thinning intensity in three forest sites in north-western Patagonia with contrasting tree height ('Tall', 'Medium' and 'Short'). Each point is the average value of a plot, and lines are the predicted values from mixed-effects models. For pollinators, the dotted line represents the model shared by the three sites.

Changes in pollinator evenness may be attributed mainly to an abrupt increase in density of one or two species/morphospecies over the rest (Appendix S2). At the Tall shrubland, these species were mainly $R$. mutabilis, followed by the group of other Andrenidae and small solitary bees (Halictidae) (Bee 1 and Bee 2 at Appendix S2). At the Medium shrubland, we observed no consistent changes in relative densities. At the Short shrubland, density of one coleopteran morphospecies increased steeply over the rest (Buprestidae sp1; Beetle2 in Appendix S2). In general, species occurring at thinned plots and not at control plots ( $0 \%$ thinning) were usually in low abundance (grey dots at 70\% Appendix S2). Among pollinator species that only occurred at control plots, and thus may be especially vulnerable to thinning, are the Nemestrinidae fly Tricophtalma porteri and the solitary bee Chalepogenus caeruleus (grey dots at $0 \%$ Appendix S2).

\section{DISCUSSION}

Understanding how disturbance affects biodiversity at different trophic levels is key for sustainable management of natural resources. Flower and pollinator abundance and diversity are usually positively related (Ebeling et al. 2008), so we expected pollinator responses to thinning to follow those of flowers. Here, the only relatively consistent positive 
Table 1. Response variables correlation. Spearman's correlation coefficients among density, richness and evenness of plants, flowers and pollinators. Significant results are highlighted in bold $(P<0.05)$

\begin{tabular}{|c|c|c|c|c|c|c|c|c|c|c|}
\hline & & & \multicolumn{3}{|c|}{ Density } & \multicolumn{3}{|c|}{ Richness (Chao1) } & \multicolumn{2}{|c|}{$\begin{array}{l}\text { Evenness } \\
(\text { EinvD) }\end{array}$} \\
\hline & & & $\begin{array}{l}\text { Plants (Log } \\
\left.\left(\text { No. } \mathrm{m}^{-2}\right)\right)\end{array}$ & $\begin{array}{l}\text { Flowers }(\log \\
\left.\left(\text { No. } \mathrm{m}^{-2}\right)\right)\end{array}$ & $\begin{array}{c}\text { Visitors } \\
\left(\text { No. } \min ^{-1} \mathrm{~m}^{-2}\right)\end{array}$ & Plants & Flowers & Visitors & Plants & Flowers \\
\hline \multirow{8}{*}{$\begin{array}{c}\text { Year } \\
1\end{array}$} & Density & Flowers & -0.42 & & & & & & & \\
\hline & & Visitors & -0.27 & 0.84 & & & & & & \\
\hline & Richness & Plants & -0.23 & 0.59 & 0.42 & & & & & \\
\hline & & Flowers & -0.22 & 0.76 & 0.74 & 0.60 & & & & \\
\hline & & Visitors & -0.15 & 0.37 & 0.17 & 0.33 & 0.36 & & & \\
\hline & Evenness & Plants & -0.12 & -0.06 & 0.02 & -0.37 & -0.02 & -0.08 & & \\
\hline & & Flowers & -0.10 & -0.44 & -0.57 & -0.11 & -0.57 & -0.31 & -0.04 & \\
\hline & & Visitors & 0.01 & -0.30 & -0.52 & -0.07 & -0.27 & -0.48 & -0.15 & 0.32 \\
\hline \multirow{8}{*}{$\begin{array}{c}\text { Year } \\
2\end{array}$} & Density & Flowers & -0.21 & & & & & & & \\
\hline & & Visitors & -0.32 & 0.92 & & & & & & \\
\hline & Richness & Plants & -0.22 & 0.57 & 0.51 & & & & & \\
\hline & & Flowers & 0.26 & 0.34 & 0.25 & 0.74 & & & & \\
\hline & & Visitors & -0.22 & 0.38 & 0.42 & 0.33 & 0.42 & & & \\
\hline & Evenness & Plants & -0.49 & -0.12 & -0.03 & -0.08 & -0.17 & 0.00 & & \\
\hline & & Flowers & 0.05 & -0.50 & -0.37 & -0.75 & -0.58 & 0.01 & -0.04 & \\
\hline & & Visitors & -0.57 & 0.29 & 0.36 & -0.02 & -0.36 & -0.03 & 0.16 & 0.11 \\
\hline
\end{tabular}

relationship between flowers and pollinators was in terms of density, but flowers and pollinators did not respond similarly to increasing thinning intensity. In particular, pollinator density showed stronger responses to thinning intensity at the sites where flower density showed weaker response to thinning and vice versa. Therefore, our results highlight a decoupling between the short-term response of flowers and pollinators to thinning in north-western Patagonia.

Pollinator density and richness increased with thinning independently of plants and flowers. This finding supports the hypothesis that pollinator response to thinning is governed more by changes in flower attractiveness, abiotic conditions or vegetation structure, rather than small-scale changes in flower density and richness. One possibility is that for mobile organisms, such as pollinators, detectability and accessibility to resources may be more important than resource abundance in determining patch choice. Thinning reduced the number of trees but could have increased flower production per individual (Cunningham 1997), in addition to increasing nectar and pollen production quantity and/or quality per flower (Boose 1997; Etterson \& Galloway 2002; Baude et al. 2011), making individual flower patches more isolated but more conspicuous and rewarding, and thus more attractive (Charnov 1976; Goulson 1999; Ohashi \& Yahara 2002). Another non-exclusive mechanism is that abiotic conditions introduced by thinning, especially the increase in light and temperature could enhance pollinator activity and diversity (Herrera 1995). This is consistent with the fact that in the Tall shrubland, where tree cover is greater and light more limiting, the enhancing effect of thinning on pollinator activity is the greatest, whereas in the Short shrubland this effect is the weakest. The percentage of bare soil, although not evaluated here, is another abiotic factor that may also increase with thinning intensity and may provide greater nesting availability, contributing directly to pollinator density and richness (Rodriguez \& Kouki 2015). Therefore, our results provide evidence that changes in vegetation structure and abiotic factors in temperate forest systems are key drivers of pollinator density and richness.

Overall, evenness response to thinning was weaker than richness. Only pollinators' evenness marginally responded, with a decrease at high levels of thinning. Although it seems to be logical that disturbance may affect pollinators differently, we do not recognise any general trait that may be associated with thinning effects on evenness. Only at the Tall shrubland, we could relate decrease in evenness with a steep increase in small soil-nesting bees at high thinning intensity. Other studies have also reported association between soil-nesting bees and disturbance (Williams et al. 2010), and small-sized bees associated with a smaller grain size response to resources given their more restricted foraging range (Torné-Noguera et al. 2014). In any event, thinning did not seem to have affected the relative abundance of soil-nesting bees at the Medium and Short shrublands, suggesting that soil-nesting resources are only limiting at the Tall shrubland. Evenness for both plants and flowers was highly variable among plots, which may be accounted for a rapid turnover of species with individuals with very different traits. In general, richness and evenness indices were 

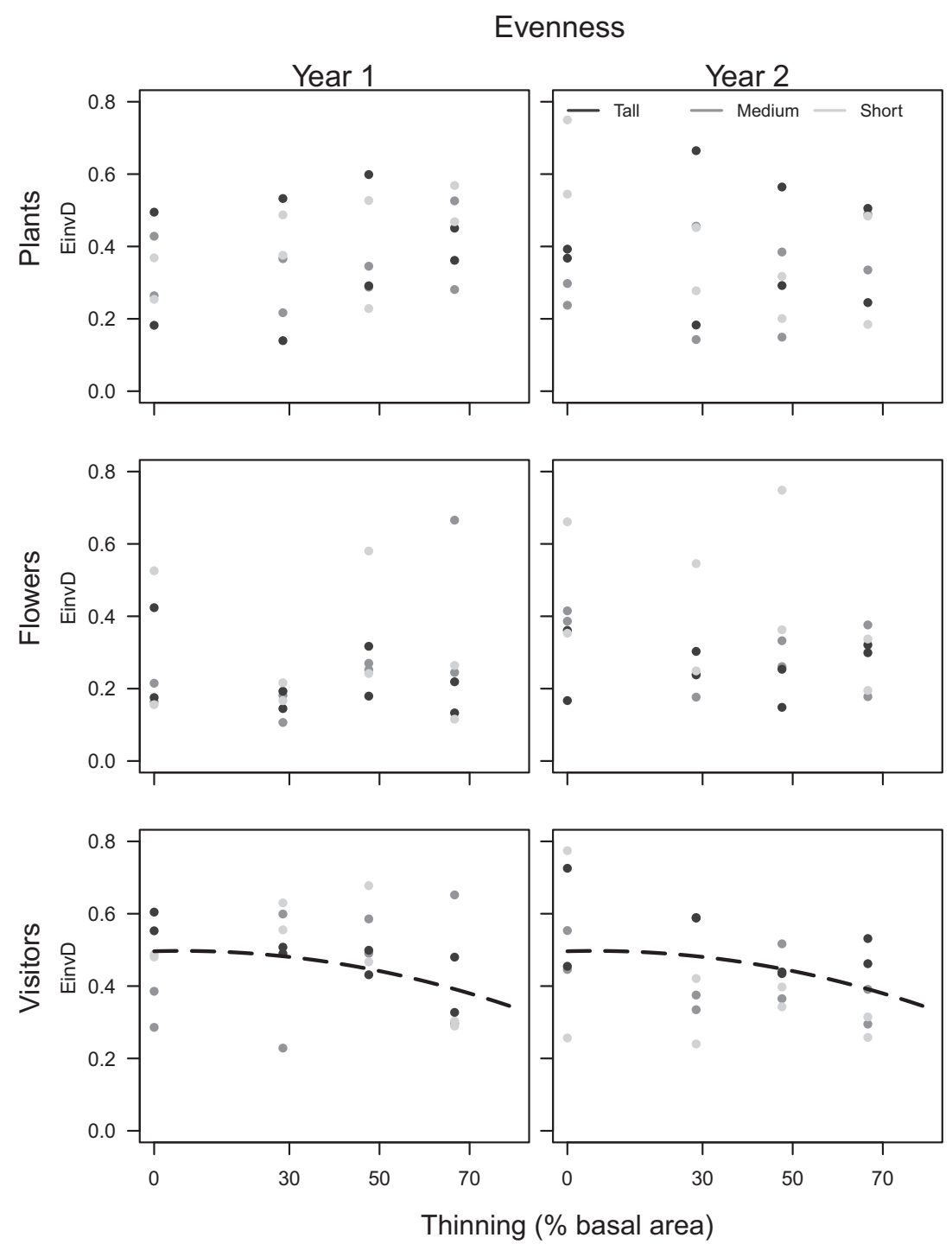

Fig. 4. Plant, flower and pollinator evenness. Plant, flower and pollinator evenness responses to thinning intensity in three forest sites in north-western Patagonia with contrasting tree height ('Tall', 'Medium' and 'Short'). Each point is the average value of a plot, and lines are the predicted values from mixed-effects models. For pollinators, the dotted line represents the model shared by the three sites.

negatively related or not significantly related at all, supporting the fact that these variables alone, as well as other diversity indices, are not enough for representing the complexity of diversity (Wilsey et al. 2005; Bock et al. 2007; MacDonald et al. 2017).

Plant and flower richness varied with thinning intensity and among sites, but not in accordance with tree stratum height as expected by the dynamic equilibrium model. Maximum richness was expected at higher thinning intensities in the Tall shrubland, while the inverse was expected in the Short shrubland. Although unexpected, our results may be a consequence of differences in community composition. At the Short shrubland, the most common trees are non-entomophilous flowering species; therefore, entomophilous flowers are mostly produced by herbs and shrubs, which are favoured by thinning. Consequently, in this case, thinning acts less as a disturbance and more as a resource liberation factor (light, soil resources, etc.), thus explaining the accelerated increase in richness along with thinning intensity.

Pollinator richness, besides not following plant and flower responses to thinning, did not respond as expected by intermediate disturbance hypothesis and dynamic equilibrium model. Nevertheless, the relationship among trophic levels after disturbances at a large spatial scale may have different responses from the ones we show here, as other landscape and population factors may greatly influence pollinator responses (Steffan-Dewenter 2003). Thus, DEM prediction for 
pollinator responses may be working at larger spatial scales, while at the plot scale pollinator richness is positively affected by forest thinning.

Pollination is crucial for plant reproductive success, and pollinator abundance and diversity increase this ecological function in most systems (Garibaldi et al. 2013; Winfree et al. 2018). Increases in species richness are considered to be positive for ecosystem functioning, because species vary in functionality and in their capacity to respond to perturbations (Hooper et al. 2005). Although a decrease in evenness is considered to be related to a decrease in function efficiency (Mason et al. 2005; Fontaine et al. 2006), the fact that pollinator abundance and richness increased sharply (and evenness decreased marginally) with thinning intensity suggests that pollinator functionality could be favoured in woodland patches after a small-scale disturbance, ensuring plant reproductive success (Klein et al. 2003; Albrecht et al. 2012; Blaauw \& Isaacs 2014a,b). However, pollination service in the neighbouring forest may be reduced via pollinator-mediated competition between scattered and low-density flowering patches in the forest and the more attractive flowering patches of disturbed areas (Cartar 2005; Pengelly \& Cartar 2010). In summary, the increased pollinator richness and abundance after thinning is promising for plant recovery in disturbed patches, although a demographic response at the landscape scale remains to be tested.

Here, pollinator abundance, richness and evenness responses to thinning were independent of plant and flower responses. Our findings highlight that woodland disturbance effects on plants and flower community attributes are different in terms of directions and magnitudes depending on the specific site characteristics and species composition. Particularly, short-term thinning effects on pollinator community at this scale are weakly related to changes in flower species abundances. Patterns of pollinator responses to small-scale thinning were very robust, with a consistent effect among sites and years, especially for pollinator richness. For both plants and pollinators, evenness showed weaker responses to thinning than abundance and richness, implying that it is important to analyse the different components of diversity. Therefore, it is clear that tree thinning conducted at a small scale enhances pollinator presence at Northern Patagonia shrublands, suggesting that a small-scale forest management that preserves surrounding undisturbed forest can be recommended among sustainable forestry practices for the many benefits it provides.

\section{ACKNOWLEDGEMENTS}

We thank F. Oddi, F. Miguez, M. Garrat, N. Pérez Méndez, M. Goldenberg, C. Bosc, I. Cancio and J.
Hipólito, together with anonymous reviewers and the editors who made valuable comments on previous versions of the manuscript, W. Rifo, P. Nuñez and J. I. Agüero who assisted in the field and J.P. Torreta, R. Gonzalez Vaquero, T. Mahlmann, A. Roig Alsina, P. Mulieri, L. Campagnucci, M. A. Alma and J. Puntieri who helped with taxonomic identification. We are also grateful to Ubuntu's and R's developers and contributors for making science available to everyone.

\section{FUNDING}

This work was supported by the Agencia Nacional de Promoción Científica y Tecnológica [grant PICT2013-1079 and PICT 2016-0305].

\section{REFERENCES}

Aizen M. A. (2001) Flower sex ratio, pollinator abundance, and the seasonal pollination dynamics of a protandrous plant. Ecology 82, 127-44.

Aizen M. A. \& Ezcurra C. (1998) High incidence of plantanimal mutualisms in the woody flora of the temperate forest of southern South America: biogeographical origin and present ecological significance. Ecol. Austral. 8, 21736.

Aizen M. A. \& Vazquez D. P. (2006) Flower Performance in Human-Altered Habitats. In Ecology and Evolution of Flowers (eds L. D. Harder \& S. C. H. Barrett), pp. 15980. Oxford University Press, Oxford, UK.

Albrecht M., Schmid B., Hautier Y. \& Muller C. B. (2012) Diverse pollinator communities enhance plant reproductive success. Proc. R. Soc. B Biol. Sci. 279, 4845-52.

Bartón K. (2016) MuMIn: Multi-model inference. [online]. Available from: https://cran.r-project.org/web/packages/ MuMIn.

Baude M., Leloup J., Suchail S. et al. (2011) Litter inputs and plant interactions affect nectar sugar content. F. Ecol. 99, 828-37.

Blaauw B. R. \& Isaacs R. (2014a) Flower plantings increase wild bee abundance and the pollination services provided to a pollination-dependent crop. F. Appl. Ecol. 51, 890-8.

Blaauw B. R. \& Isaacs R. (2014b) Larger patches of diverse floral resources increase insect pollinator density, diversity, and their pollination of native wildflowers. Basic Appl. Ecol. 15, 701-11.

Bock C. E., Jones Z. F. \& Bock J. H. (2007) Relationships between species richness, evenness, and abundance in a southwestern savanna. Ecology 88, 1322-7.

Boose D. L. (1997) Sources of variation in floral nectar production rate in Epilobium canum (Onagraceae): implications for natural selection. Oecologia 110, 493-500.

Brose U. (2003) Bottom-up control of carabid beetle communities in early successional wetlands: mediated by vegetation structure or plant diversity? Oecologia 135, 40713.

Burgess V. J., Kelly D., Robertson A. W. \& Ladley J. J. (2006) Positive effects of forest edges on plant reproduction: literature review and a case study of bee visitation to 
flowers of Peraxilla tetrapetala (Loranthaceae). N. Z. F. Ecol. 30, 179-90.

Canham C. D., Denslow J. S., Platt W. J., Runkle J. R., Spies T. A. \& White P. S. (1990) Light regimes beneath closed canopies and tree-fall gaps in temperate and tropical forests. Can. F. For. Res. 20, 620-31.

Cartar R. V. (2005) Short-term effects of experimental boreal forest logging disturbance on bumble bees, bumble beepollinated flowers and the bee-flower match. Biodivers. Conserv. 14, 1895-907.

Cavallero L., López D. R., Raffaele E. \& Aizen M. A. (2015) Structural-functional approach to identify post-disturbance recovery indicators in forests from northwestern Patagonia: a tool to prevent state transitions. Ecol. Indic. 52, 85-95.

Chalcoff V. R., Aizen M. A. \& Galetto L. (2006) Nectar concentration and composition of 26 species from the temperate forest of South America. Ann. Bot. 97, 413-21.

Charnov E. L. (1976) Optimal foraging, the marginal value theorem. Theor. Popul. Biol. 9, 129-36.

Colwell R. K. (2013) EstimateS: Statistical estimation of species richness and shared species from samples. Version 9., http://purl.oclc.org/estimates.

Connell J. H. (1978) Diversity in tropical rain forests and coral reefs. Science (80-.). 199, 1302-10.

Cunningham S. A. (1997) The effect of light environment, leaf area, and stored carbohydrates on inflorescence production by a rain forest understory palm. Oecologia 111, 36-44.

Ebeling A., Klein A. M., Schumacher J., Weisser W. W. \& Tscharntke T. (2008) How does plant richness affect pollinator richness and temporal stability of flower visits? Oikos 117, 1808-15.

Etterson J. R. \& Galloway L. F. (2002) The influence of light on paternal plants in Campanula Americana (Campanulaceae): pollen characteristics and offspring traits. Am. F. Bot. 89, 1899-906.

Fontaine C., Dajoz I., Meriguet J. \& Loreau M. (2006) Functional diversity of plant-pollinator interaction webs enhances the persistence of plant communities. PLoS Biol. 4, 0129-35.

Fox J. W. (2013) The intermediate disturbance hypothesis should be abandoned. Trends Ecol. Evol. 28, 86-92.

Frund J., Dormann C. F., Holzschuh A. \& Tscharntke T. (2013) Bee diversity effects on pollination depend on functional complementarity and niche shifts. Ecology 94, 2042-54.

Garibaldi L. A., Steffan-Dewenter I., Kremen C. et al. (2011) Stability of pollination services decreases with isolation from natural areas despite honey bee visits. Ecol. Lett. 14, 1062-72.

Garibaldi L. A., Steffan-Dewenter I., Winfree R. et al. (2013) Wild pollinators enhance fruit set of crops regardless of honey bee abundance. Science (80-.). 339, 1608-11.

Gerstner K., Dormann C. F., Stein A., Manceur A. M. \& Seppelt R. (2014) Effects of land use on plant diversity - A global meta-analysis. F. Appl. Ecol. 51, 1690-700.

Goulson D. (1999) Foraging strategies of insects for gathering nectar and pollen, and implications for plant ecology and evolution. Perspect. Plant Ecol. Evol. Syst. 2, 185-209.

Grime J. P. (1973) Competitive exclusion in herbaceous vegetation. Nature 242, 344-7.

Hautier Y., Tilman D., Isbell F., Seabloom E. W., Borer E. T. \& Reich P. B. (2015) Anthropogenic environmental changes affect ecosystem stability via biodiversity. Science 348, 336-40.
Herrera C. M. (1995) Microclimate and individual variation in pollinators: flowering plants are more than their flowers. Ecology 76, 1516-24.

Hooper D. U., Chapin F. S., Ewel J. J. et al. (2005) Effects of biodiversity on ecosystem functioning: a consensus of current knowledge. Ecol. Monogr. 75, 3-35.

Hortal J., Borges P. A. V \& Gaspar C. (2006) Evaluating the performance of species richness estimators: sensitivity to sample grain size. F. Anim. Ecol. 75, 274-87.

Hunter M. D. \& Price P. W. (1992) Playing chutes and ladders: heterogeneity and the relative roles of bottom-up and top-down forces in natural communities. Ecology 73, 724-32.

Huston M. A. (1979) A general hypothesis of species diversity. Am. Nat. 113, 81-101.

Huston M. A. (2014) Disturbance, productivity, and species diversity: empiricism versus logic in ecological theory. Ecology 95, 2382-96.

Instituto de Botánica Darwinion (2016). Catálogo de la Flora Vascular de Argentina. Retrieved from http://www.floraarge ntina.edu.ar

Klein A. M., Steffan-Dewenter I. \& Tscharntke T. (2003) Pollination of Coffea canephora in relation to local and regional agroforestry management. f. Appl. Ecol. 40, 83745.

Lantschner M. V. \& Rusch V. (2007) Impacto de diferentes disturbios antrópicos sobre las comunidades de aves de bosques y matorrales de Nothofagus antarctica en el NO Patagónico. Ecol. Austral 17, 99-112.

MacDonald Z. G., Nielsen S. E. \& Acorn J. H. (2017) Negative relationships between species richness and evenness render common diversity indices inadequate for assessing long-term trends in butterfly diversity. Biodivers. Conserv. 26, 617-29.

Mason N. W. H., Mouillot D., Lee W. G. \& Wilson J. B. (2005) Functional richness, functional evenness and functional divergence: the primary components of functional diversity. Oikos 111, 112-8.

Morales C. L. \& Aizen M. A. (2006) Invasive mutualisms and the structure of plant-pollinator interactions in the temperate forests of north-west Patagonia. Argentina. $\mathcal{F}$. Ecol. 94, 171-80.

Newbold T., Hudson L. N., Arnell A. P. et al. (2016) Has land use pushed terrestrial biodiversity beyond the planetary boundary? A global assessment. Science 353, 288-91.

Ohashi K. \& Yahara T. (2002) Visit larger displays but probe proportionally fewer flowers: counterintuitive behaviour of nectar-collecting bumble bees achieves an ideal free distribution. Funct. Ecol. 16, 492-503.

Oksanen J., Blanchet F. G., Friendly M. et al. (2017) vegan: Community Ecology Package. [online]. Available from: https://cran.r-project.org/package=vegan.

Ollerton J., Winfree R. \& Tarrant S. (2011) How many flowering plants are pollinated by animals? Oikos 120, 3216.

Paritsis J., Raffaele E. \& Veblen T. T. (2006) Vegetation disturbance by fire affects plant reproductive phenology in a shrubland community in northwestern Patagonia, Argentina. N. Z. F. Ecol. 30, 387-95.

Pengelly C. J. \& Cartar R. V. (2010) Effects of variable retention logging in the boreal forest on the bumble beeinfluenced pollination community, evaluated 8-9 years post-logging. For. Ecol. Manage. 260, 994-1002. 
Pinheiro J., Bates D., DebRoy S., Sarkar D. \& Team R. C. (2017) nlme: Linear and Nonlinear Mixed Effects Models. $\mathrm{R}$ package version 3.1.

R Core Team (2018) R: A language and environment for statistical computing.

Reque J. A., Sarasola M., Gyenge J. \& Fernández M. E. (2007) Caracterización silvícola de ñirantales del norte de la Patagonia para la gestión forestal sostenible. Bosque (Valdivia) 28, 33-45.

Rodriguez A. \& Kouki J. (2015) Emulating natural disturbance in forest management enhances pollination services for dominant Vaccinium shrubs in boreal pine-dominated forests. For. Ecol. Manage. 350, 1-12.

Rodríguez A. \& Kouki J. (2017) Disturbance-mediated heterogeneity drives pollinator diversity in boreal managed forest ecosystems. Ecol. Appl. 27, 589-602.

Rusch V., Lopez D. R., Cavallero L. et al. (2017) Modelo de estados y transiciones de los ñirantales del NO de la Patagonia como herramienta para el uso silvopastoril sustentable. Ecol. Austral. 27, 266-78.

Saturni F. T., Jaffé R. \& Metzger J. P. (2016) Landscape structure influences bee community and coffee pollination at different spatial scales. Agric. Ecosyst. Environ. 235, 112.

Scherber C., Eisenhauer N., Weisser W. W. et al. (2010) Bottom-up effects of plant diversity on multitrophic interactions in a biodiversity experiment. Nature 468, 553-6.

Sekercioglu C. H. (2002) Effects of forestry practices on vegetation structure and bird community of Kibale National Park, Uganda. Biol. Conserv. 107, 229-40.

Siemann E. (1998) Experimental tests of effects of plant productivity and diversity on grassland arthropod diversity. Ecology 79, 2057-70.

Smith B. \& Wilson J. B. (1996) A Consumer's Guide to Evenness Indices A consumer's guide to evenness indices. Oikos 76, 70-82.

Steffan-Dewenter I. (2003) Importance of habitat area and landscape context for species richness of bees and wasps in fragmented orchard meadows. Conserv. Biol. 17, 1036-44.

Torné-Noguera A., Rodrigo A., Arnan X. et al. (2014) Determinants of spatial distribution in a bee community: nesting resources, flower resources, and body size. PLoS ONE 9, 1-10.
Vrdoljak S. M., Samways M. J. \& Simaika J. P. (2016) Pollinator conservation at the local scale: flower density, diversity and community structure increase flower visiting insect activity to mixed floral stands. F. Insect Conserv. 20, 711-21.

Weng S. H., Kuo S. R., Guan B. T., Chang T. Y., Hsu H. W. \& Shen C. W. (2007) Microclimatic responses to different thinning intensities in a Japanese cedar plantation of northern Taiwan. For. Ecol. Manage. 241, 91-100.

Williams N. M., Crone E. E., Roulston T. H., Minckley R. L., Packer L. \& Potts S. G. (2010) Ecological and life-history traits predict bee species responses to environmental disturbances. Biol. Conserv. 143, 2280-91.

Wilsey B. J., Chalcraft D. R., Bowles C. M. \& Willig M. R. (2005) Relationships among indeces suggest that richness is an incomplete surrogate for grassland biodiversity. Ecology 86, 1178-84.

Winfree R., Griswold T. \& Kremen C. (2007) Effect of human disturbance on bee communities in a forested ecosystem. Conserv. Biol. 21, 213-23.

Winfree R., Aguilar R., Vazquez D. P., LeBuhn G. \& Aizen M. A. (2016) A meta-analysis of bees' responses to anthropogenic disturbance. Ecology 97, 302-12.

Winfree R., Reilly J. R., Bartomeus I., Cariveau D. P., Williams N. M. \& Gibbs J. (2018) Species turnover promotes the importance of bee diversity for crop pollination at regional scales. Science 359, 791-3.

\section{SUPPORTING INFORMATION}

Additional supporting information may/can be found online in the supporting information tab for this article.

Appendix S1. Study sites map.

Appendix S2. Pollinators density at 0 and $70 \%$ thinning levels at each site.

Appendix S3. Relative importance of each predictor variable for the general model.

Appendix S4. Estimated values for each predictor variable in the models. 